\title{
Inovação em tempos difíceis
}

\author{
Innovation in difficult times
}

Glauco Arbix e Zil Mirandab

\begin{abstract}
Resumo A baixa produtividade está na raiz das dificuldades da economia brasileira e na sua capacidade de sustentar longos ciclos de crescimento e de geração de empregos de qualidade. Estagnada desde os anos 1970, a agenda da economia tem um ponto chave: como superar o baixo desempenho estrutural da nossa economia? Infraestrutura, sistema tributário, baixo grau de competição e sistema regulatório inadequado despontam como itens de primeira importância. Mas é somente a elevação das habilidades de quem trabalha que permitirá a integração entre pessoas, ideias, tecnologia, processos e modelos de produção mais avançados. É o que dá ao conhecimento a capacidade de mover os mecanismos da economia. Esse processo atende pelo nome de inovação. E a capacidade de incorporar, adaptar e produzir inovações de modo ininterrupto é fundamental para viabilizar ganhos crescentes de eficiência na atividade econômica. É o que a economia mais urgentemente precisa. Esse é o foco da agenda capaz de conectar o Brasil com o futuro.
\end{abstract}

Palavras-chave Produtividade; Ciência; Tecnologia \& Inovação; Agenda para o Desenvolvimento.

Abstract Low productivity is at the basis of Brazilian economy difficulties and in its capacity of supporting long cycles of growth and quality jobs creation. Stagnant since the 1970s, the economic agenda has a central point: how do to overcome the low structural performance of Brazilian economy? Infrastructure, tax system, low degree of competition and an inappropriate regulatory system rise as items of first importance. However, only the increase of workers' skills will enable the integration of people, ideas, technologies, processes and more advanced production models. Thus giving knowledge the capacity to move economy's mechanisms. Such a process is called innovation. And the capacity of uninterruptedly incorporating, adapting and producing innovation is key to facilitate increased efficiency results in economic activities. This is what economy most urgently needs. It is the focus item in the agenda that will connect Brazil to the future.

Keywords Productivity; Science; Technology \& Innovation; Development Agenda.

a Professor titular do Departamento de Sociologia da USP e pesquisador do Observatório da Inovação - IEA-USP.

b Doutora em Sociologia (USP) e assessora da Agência Brasileira de Desenvolvimento Industrial -ABDI. 


\section{INTRODUÇÃO}

Nunca houve caminho fácil nem atalhos para o desenvolvimento dos países. Os obstáculos tornam-se ainda maiores e mais complexos quando o ritmo da economia mundial é de estagnação ou de recuperação lenta, com anunciados desdobramentos ao longo do tempo.

No Brasil de hoje, a fusão entre a crise econômica e política drena a representatividade do governo, questiona até mesmo sua legitimidade e, mais importante, ameaça engolir avanços sociais relevantes alcançados nos últimos anos. O grave é que o debate público sobre as alternativas para a economia sofre com o assédio da crise. Questões não resolvidas há décadas afloram muitas vezes desordenadamente e fomentam uma profusão de narrativas, oficiais e não oficiais, que pretendem anunciar as saídas para a paralisia do governo e a retomada do crescimento do país.

No entanto, é preciso trabalhar com foco e prioridades para delimitar a extensão da agenda econômica e abrir uma linha de futuro para o país. Alcançar equilíbrio fiscal, recuperar o controle sobre a inflação, trazendo-a para o centro da meta, e manter o câmbio e os juros nos limites adequados para um país como o nosso (ainda que a adequação seja sempre polêmica) são pilares essenciais de uma economia sadia. Mas a estruturação de uma política de médio e longo prazo exige diagnóstico mais preciso dos problemas que afligem a economia.

Se queremos encontrar caminhos para o crescimento econômico, capaz de gerar emprego e renda, que seja sustentável e inclusivo, o primeiro passo é reconhecer que a nossa economia é de baixo desempenho, com exceção de raros nichos. Ou seja, uma economia que vive, estruturalmente, uma compressão em seus índices de produtividade, em especial os da indústria, o que a torna menos competitiva no mercado nacional e internacional, com todas as implicações decorrentes para o crescimento e a geração de empregos de qualidade.

O crescimento econômico tem com a produtividade uma relação de dependência crítica. $\mathrm{O}$ crescimento de longo prazo está diretamente relacionado à capacidade de as economias produzirem mais com a mesma quantidade de trabalho. Sem aumento de produtividade, a elevação dos padrões de vida e os processos de inclusão com diminuição agressiva da pobreza só ocorrem graças a condicionantes externos excepcionais - como o aumento da demanda por commodities, puxado basicamente pela China, com forte impacto no Brasil até 2010.

O fato é que no Brasil a produtividade está praticamente estagnada desde o final da década de 1970, ou seja, mesmo após ter passado pelo crivo de diferentes orientações econômicas. Trabalhos recentes do IPEA abordaram a trajetória da 
produtividade com distintas metodologias de aferição e reafirmaram os sinais emitidos por uma economia que não dá conta do ritmo da demanda, que vê a retração da indústria e a perda de espaço no comércio internacional e que responde apenas por espasmos aos estímulos de crescimento (cf. De NeGRI; CAVAlCANTE, 2014, v. 1).

Efeitos desse crônico mal-estar se manifestaram mesmo nos breves intervalos de crescimento, que contou com apoio apenas marginal da produtividade. Majoritariamente, o bom desempenho brasileiro se deu sustentado pelo aumento da força de trabalho ocupada, ou seja, por uma maior participação de trabalhadores no mercado de trabalho.

As alternativas para quebrar essa continuidade viciosa nem sempre são claras. Para além das distorções geradas pelo debate público contaminado pela crise, o importante é que as pesquisas mais sérias sobre o que deflagra a recuperação do crescimento não são conclusivas. A incerteza é semelhante quando se trata de definir o que os governos podem fazer para interferir positivamente em situações de estagnação - as falas mais frequentes apontam o que os governantes não devem fazer e, em geral, ocorrem post factum.

Certamente nossas dificuldades residem na frágil infraestrutura, nos desequilíbrios do sistema tributário e nos baixos índices de concorrência que marcam a economia. É o que nos ajuda a entender a participação declinante do Brasil no comércio internacional e a pálida ligação do sistema produtivo às correntes mais dinâmicas que movem a economia global. A crise e o baixo nível de investimento completam o quadro de variáveis-chave que explicam nossa baixa produtividade.

No entanto, décadas de estagnação orientam nosso olhar para dimensões subestimadas (ou mesmo esquecidas) ao longo do tempo, dadas as dificuldades de sua adequação aos modelos que norteiam o discurso econômico mais corrente.

Produtividade ganha sentido pleno quando relacionada ao trabalho mais inteligente, ou seja, mais embebido de conhecimento. Precisamente porque é somente a elevação das habilidades de quem trabalha que permite a integração mais equilibrada entre as pessoas, ideias, tecnologia e modelos de produção mais avançados. Esse processo que dá concretude ao conhecimento e o faz capaz de movimentar os mecanismos da economia atende pelo nome de inovação. E a capacidade de incorporar, adaptar e produzir inovações de modo ininterrupto é fundamental para viabilizar ganhos crescentes de eficiência na atividade econômica. É a debilidade dessa dinâmica que mais castiga a economia brasileira.

O sentido integral desse diagnóstico nos leva a conclusões capazes de orientar as políticas públicas: o Brasil precisa priorizar e concentrar esforços e recursos 
para consolidar uma cultura de inovação em todas as dimensões da atividade econômica. Por isso mesmo, a elevação do patamar de pesquisa e desenvolvimento (P\&D) das empresas e a busca obstinada da diminuição do gap que separa nossa economia da dos países que produzem na fronteira do conhecimento são os únicos caminhos que levam à reversão da trajetória de baixo desempenho.

Sem esse esforço, que exige cooperação entre os setores público e privado, não haverá alteração profunda da estrutura produtiva, condição para sustentar ciclos longos de elevação da produtividade. $O$ tamanho do desafio recomenda a decisão estratégica de concentrar as atenções e o investimento de nossos limitados recursos em educação, ciência, tecnologia e inovação (CT\&I). Sem a estabilidade dada por políticas de longa duração, dificilmente essa concentração de esforços apresentará os resultados esperados. Miopia política e Educação, CT\&I são incompatíveis.

\section{MAS $O$ QUE FAZER EM TEMPOS DIFÍCEIS?}

Por mais paradoxal que possa parecer, os momentos de crise são os mais apropriados para se evitar a diluição da centralidade que a Educação, Ciência, Tecnologia e Inovação (CT\&I) têm para países como o nosso.

Muitos países avançados - e também nossos concorrentes mais diretos, como Índia, China, África do Sul e outros - preparam-se aceleradamente para participar da próxima onda que anuncia uma revolução no modo de produção industrial. Esse futuro acena com uma indústria avançada, que se caracteriza por maior dependência das tecnologias de informação e comunicação, pelo uso de equipamentos e máquinas mais conectados em redes (inclusive robôs) e pela operação de quantidades de informações em volume muito superior ao que estamos acostumados nos dias de hoje (big data).

Esses novos conceitos derivam de outros ainda nem tão familiares para muitos de nós, como o da internet das coisas e o da comunicação máquina-máquina, que se baseiam na lógica da conexão de dispositivos e troca de informação entre diferentes componentes e sistemas. Países como Estados Unidos e Alemanha investem prioritariamente nessas tecnologias, buscando redução de custos e do tempo de produção, menor consumo de energia, maior segurança aos trabalhadores, entre outros benefícios. Trata-se de novas modalidades de organização da produção, que elevam a qualidade e a eficiência da indústria, extrapolam o mundo fabril e apontam para novas dimensões de consumo, de cultura e de sociabilidade. $\mathrm{O}$ Brasil, que já perdeu o bonde da microeletrônica e das tecnologias de informação e comunicação, não deve fechar os olhos para essas novas tendências. Não por 
qualquer modismo, mas pela necessidade de promover uma reviravolta em seu sistema produtivo.

As janelas de oportunidade para os países em desenvolvimento fecham-se mais a cada dia. A concorrência por custo, qualidade e salário, com enormes sacrifícios para a população, está com seus dias contados. A revolução em curso no universo da produção, com impactos diretos no mercado de trabalho - modificando profissões, transformando ocupações e aumentando a concorrência entre trabalhadores e a desigualdade entre os mais e os menos qualificados -, é fonte ainda de maior instabilidade para as sociedades.

As ameaças concretas aos avanços sociais alcançados no Brasil nos últimos anos certamente serão amplificadas se nossa economia não conseguir acompanhar o ritmo da evolução produtiva.

É razoável afirmar que, nos anos 2000, o Brasil começou a escrever um novo capítulo de sua história. Dessa vez, marcado por políticas combinadas de crescimento econômico e distribuição de renda. Um novo padrão de desenvolvimento começou a se configurar. Na agenda implementada, a ideia de um novo ativismo de Estado combinou-se com uma colaboração e diálogo estreito com o meio empresarial e os mercados. Os esforços pela educação de qualidade e as políticas de inovação que começaram a tomar corpo expressavam essa preocupação. Desde então, registraram-se avanços importantes no ambiente brasileiro, que se tornou mais amigável à inovação, com novos instrumentos e programas. Mas políticas desse perfil exigem tempo e estabilidade para sua maturação. $\mathrm{O}$ acúmulo de equívocos na condução da economia e as incertezas que se avolumaram na Educação, CT\&I colocam em risco uma série de avanços sociais importantes.

\section{DESAFIOS E CONQUISTAS}

Não há caminho fácil nem atalhos para o desenvolvimento dos países. Ainda mais quando o ritmo de recuperação da economia mundial é baixo ou mesmo inexistente em algumas regiões. No Brasil, a crise política associada à queda aguda da atividade econômica expõe problemas estruturais que, certamente, inibirão ainda mais o investimento e ensejarão um reordenamento rigoroso da aplicação dos recursos públicos. No entanto, a história de vários países ensina que nos momentos de crise é que não se pode diluir o foco necessário que Educação, CT\&I devem ter.

As nações que avançaram ao longo do tempo deram especial atenção às pessoas, à sua educação e à ciência e tecnologia, mesmo em tempos difíceis. Investir sistematicamente em gente, na geração de conhecimento e em tecnologia é o que torna 
uma nação mais rica. É o que importa para milhões de pessoas que depositam esperanças nos próximos capítulos de prosperidade.

Finlândia, Coreia do Sul e Estados Unidos são exemplos de alguns países que priorizaram políticas de CT\&I em momentos de crise. Configuraram-se, de fato, como ferramentas para acelerar mudanças na economia, para a retomada do crescimento e, fundamentalmente, prepararam esses países para garantir e ampliar seu posicionamento na competição entre as nações no período pós-crise.

Na primeira metade dos anos 1990, a Finlândia mergulhou em profunda recessão. Em um intervalo de apenas quatro anos, a produção encolheu 10\% e o desemprego quadruplicou, atingindo mais de $15 \%$ da força de trabalho (OECD, 2009). Para superar as dificuldades da economia, o governo combinou medidas tradicionais - como aumento de impostos e corte de gastos para viabilizar o ajuste fiscal - com o incremento do investimento em pesquisa e desenvolvimento (P\&D), assim como em educação e infraestrutura. O resultado alcançado foi a duplicação do número de ingressantes no ensino superior e a multiplicação por quatro do número de novos alunos nas escolas politécnicas.

Essa agenda, cuidadosamente discutida com a sociedade, permitiu ao país sair da crise com uma economia maior e mais forte do que antes, com uma atividade mais complexa e diversificada, muito mais intensiva em tecnologia e conhecimento do que no período pré-crise. Na Finlândia, o destaque para as tecnologias de informação e comunicação deu novo dinamismo e elevou a competitividade de todo o país, como registrado no ranking elaborado pelo Fórum Econômico Mundial em 2005 e 2006 (ARBIX; VARON, 2009).

A experiência coreana também demonstra como uma boa gestão de períodos adversos pode acelerar ajustes estruturais (OECD, 2009). A crise que atingiu a Coreia do Sul no final dos anos 1990 causou queda no emprego de profissionais qualificados e nos investimentos privados em P\&D. Como ocorrera na Finlândia, a resposta do governo foi no sentido de investir em pesquisa, tecnologia e educação. Foram adotadas também medidas para fomentar o desenvolvimento de pequenas e médias empresas (PMEs) de base tecnológica, tais como melhorias no ambiente regulatório, incentivos fiscais e fundos de apoio à P\&D. Essas medidas contribuíram para um aumento exponencial das startups e para dobrar sua participação das mesmas nos gastos privados em P\&D, de 12\%, em 1997, para 24\%, em 2006.

Mais recentemente, encontramos nas iniciativas implementadas pelos Estados Unidos após a crise financeira de 2007-8 uma preocupação semelhante em implementar políticas de ciência e tecnologia como alavanca para a recuperação econômica. O American Recovery and Reinvestment Act (White House, 2010), 
aprovado pelo governo Barack Obama em 2009, estabeleceu diretrizes para o crescimento de longo prazo e alocou cerca de US\$ 700 bilhões para serem investidos na economia. Parte desse montante, cerca de US $\$ 100$ bilhões, foi destinada para programas de fomento à inovação. Nesse caso, as linhas mestras para a atuação do Estado foram apresentadas na Strategy for American Innovation, que destacou, entre outras medidas necessárias, o apoio à pesquisa básica, recursos humanos e infraestrutura, e a prioridade aos investimentos em energia limpa e saúde.

Inovação é a chave para a competitividade global, para a criação de novos e melhores empregos, para o fortalecimento da economia e a realização de objetivos nacionais essenciais. Essa estratégia é necessária para orientar a atuação de fundos governamentais e decisões regulatórias de modo a aproveitar as oportunidades abertas pela inovação (NATional Economic Council, 2009).

A Strategy for American Innovation já passou por duas atualizações, em 2011 e em 2015, tendo sido reafirmados os principais compromissos de sua primeira versão, como o fomento ao desenvolvimento tecnológico e os investimentos em educação, com ênfase nas engenharias, ciências e matemática. Essa estratégia contribuiu decisivamente para o aumento observado nos investimentos em P\&D, de US\$ 59 bilhões para US\$ 68 bilhões, entre 2008 e 2014 (OECD, 2014, p. 444).

Mais ainda, a partir dessa iniciativa, outros programas foram criados pelo governo para fortalecer a trajetória de inovação nas empresas, como o National Network for Manufacturing Innovation (NNMI), cujo objetivo central, inspirado na experiência dos Fraunhofer-Gesellschaft, da Alemanha, é apoiar parcerias entre universidades e empresas para o desenvolvimento de pesquisa aplicada, com vistas a solucionar problemas relevantes da indústria. O NNMI foi anunciado em 2012, com dotação orçamentária de US $\$ 1$ bilhão ao longo de dez anos. Desde então, já foram estabelecidas redes de pesquisa envolvendo dezenas de institutos para dedicarem-se ao desenvolvimento avançado da manufatura aditiva, novos materiais, fotônica e semicondutores, entre outros temas.

O Brasil tem muito a aprender com essas experiências. Se todos reconhecem que o caminho pela frente é longo, e que há muito por fazer, é flagrante também que o país ingressou nos últimos 15 anos em um novo patamar, a partir do momento em que milhões foram incluídos em um movimento virtuoso de crescimento econômico com inclusão. Desde 2001 há uma diminuição sistemática da diferença entre os rendimentos dos mais pobres e os dos mais ricos, o que resultou em um coeficiente de Gini de 0,51, em 2014, o mais baixo da história. Segundo Paes de 
Barros (2014), todas as faixas de renda beneficiaram-se do crescimento econômico, mas em especial as camadas mais carentes: entre os 10\% mais pobres, a renda cresceu 7,3\% ao ano, o equivalente a três vezes mais que a dos 10\% mais ricos.

As conquistas no combate à desigualdade também foram expressas no Índice de Desenvolvimento Humano Municipal (IDH-M), combinação de indicadores de educação, longevidade e renda. Comparando dois cenários, ano de 2000 e de 2010, é notável a diminuição do número de municípios com IDH muito baixo, em todas as regiões do país - em 2000, mais 70\% dos municípios estavam nas faixas de muito baixo e baixo Desenvolvimento Humano, ao passo que em 2010 essa proporção caiu para 25\% (PnUd, 2013; PAES DE BARros, 2014). Particularmente, chama a atenção a melhoria do indicador nas regiões Norte e Nordeste, historicamente mais castigadas pela extrema pobreza e pelo baixo desenvolvimento social, tendo sido, por essas mesmas razões, alvo de importantes ações governamentais, como o programa Bolsa Família. Fica claro, portanto, que experimentamos uma diminuição das disparidades entre o Norte e o Sul do país.

Ao mesmo tempo, essa alteração na pirâmide social pressionou (e continua pressionando) as políticas públicas em todos os níveis. Exatamente por isso, apesar de toda turbulência atual, é fundamental recusar as visões de curto prazo e reconhecer nessas mudanças o legado mais benigno dos últimos anos, pois apontam um caminho para o país equacionar problemas históricos de seu desenvolvimento.

As atenções e foco em educação, ciência e tecnologia, tanto em volume quanto em qualidade, devem obedecer à mesma lógica, na medida em que fazem parte do nosso passaporte para o futuro. Quanto mais avançada for a produção científica e tecnológica e quanto mais preparados estiverem nossos pesquisadores, maior será a possibilidade de se aumentar a capacidade inovadora das empresas. Na mesma chave, quanto mais educada e qualificada for nossa população, maiores serão as chances de renovação e evolução da estrutura social brasileira.

\section{OS AVANÇOS EM CT\&I}

A IV Conferência Nacional de CT\&I, realizada em 2010, apontou as diretrizes fundamentais que deveriam nortear nossa atividade de pesquisa: (i) Redução das desigualdades regionais e sociais; (ii) Exploração sustentável das riquezas do território nacional; (iii) Fortalecimento das empresas, agregando valor à produção e à exportação através da inovação; (iv) Reforço do protagonismo internacional do país em C\&T. 
É reconhecido que o esforço para viabilizar um salto da CT\&I no Brasil é complexo, recusa respostas únicas, assim como soluções de curto prazo. Mas a trajetória da pesquisa brasileira nos últimos anos, sua aproximação e convívio com centros internacionais que atuam na fronteira do conhecimento, permitem que o Brasil acelere o passo para fazer CT\&I de classe mundial.

Para o desenvolvimento da sociedade brasileira, é essencial que nossa CT\&I seja pautada pela busca por maior impacto, tanto na própria dimensão do conhecimento científico, quanto no âmbito social e econômico, de modo que seus resultados sejam apropriados por todas as camadas sociais.

Para tanto, ainda são válidas as recomendações da Conferência, no sentido de: (i) Consolidar o Sistema Nacional de C\&T; (ii) Formar profissionais adequados nos níveis médio e superior; (iii) Dominar as tecnologias estratégicas para o desenvolvimento nacional; (iv) Aumentar o contingente de pesquisadores nas diversas áreas de C\&T; (v) Melhorar a qualidade da educação em todos os níveis: revolução na educação; e (vi) Usar CT\&I para o desenvolvimento social.

O exame das potencialidades da C\&T brasileiras, o grau de maturidade alcançado e a qualidade dos recursos humanos acumulada sugerem que é possível elevar significativamente o padrão da nossa produção científica nos marcos de uma geração.

O Sistema Nacional de Ciência, Tecnologia e Inovação, apesar de sua juventude, ganhou estatura e se fortaleceu rapidamente nos últimos 15 anos. Porém, ainda tem dificuldades para ganhar escala, desenvoltura e formar talentos na medida exigida pelas necessidades que o país tem para se desenvolver. Em que pese sua descentralização e desconcentração (assim como o recente suporte das Fundações de Amparo que atuam em praticamente todos os estados do país), as agências de fomento, com seus mecanismos de apoio e financiamento, o rol de instrumentos, assim como sua infraestrutura de pesquisa, mostram-se insuficientes para atender a demanda atual e muito aquém do necessário para viabilizar uma elevação de patamar da produção científica e tecnológica brasileira. Nesses termos, é adequado o diagnóstico da Academia Brasileira de Ciências (ABC):

É preciso reconhecer que, não obstante os grandes avanços da ciência brasileira nas últimas décadas, o Brasil ainda segue, com raras exceções, a agenda internacional de pesquisa, o que cerceia sua liderança internacional. É necessário assim alcançar um novo patamar de desenvolvimento científico e tecnológico, em que o país seja proativo na formatação de agendas internacionais de pesquisa, na ciência básica e na inovação tecnológica (ABC, 2014, p. 3). 
Com efeito, apesar do crescimento, se mantido o padrão dos investimentos em CT\&I realizados nas últimas décadas, dificilmente o Brasil conseguirá acompanhar o ritmo de expansão da fronteira da ciência e da tecnologia mundial. Os dados da OCDE e do Eurostat mostram que, em meados da década de 2000, os investimentos empresariais como proporção do PIB cresceram na China a uma taxa de $23 \%$ e nos Estados Unidos cresceram a uma taxa de $12 \%$. O crescimento do investimento empresarial em P\&D como proporção do PIB no Brasil cresceu a uma taxa menor, cerca de 9\% (De NEGRI, 2015). Embora essa taxa fique próxima a de alguns países europeus, a escala e a qualidade de investimento em $\mathrm{P} \& \mathrm{D}$ empresarial desses países é significativamente maior do que no nosso país. O problema a ser enfrentado é que, se for mantido o atual patamar de investimento, o Brasil não conseguirá reduzir a distância que separa nossa CT\&I da dos países mais desenvolvidos.

Entre 2000 e 2013, os dispêndios em P\&D no Brasil tiveram um crescimento de $84 \%$. Para acompanhar o esforço que a China fez, por exemplo, o crescimento real teria que ser no mínimo o dobro do que foi realizado. Este crescimento foi mais intenso nos gastos do governo federal (133\%) e menor nos do setor empresarial (61\%) e dos governos estaduais (60\%). Em termos relativos, considerando-se os dispêndios em P\&D em relação ao PIB, foi observado um crescimento real de $17 \%$ no período, passando de 1,04\% do PIB (em 2000) para 1,24\% (em 2013) (Mcti, 2015). Para um país das dimensões do Brasil, seria necessário que os investimentos em P\&D atingissem no mínimo 2\% como proporção do PIB no final desta década, o que dificilmente ocorrerá.

Apesar de dotado de um arcabouço institucional relativamente moderno quando comparado às melhores práticas mundiais, o investimento em P\&D no Brasil, como proporção do PIB, não mudou de patamar na última década. O Gráfico 1 mostra que o Brasil continua muito distante da fronteira de investimento em P\&D do mundo, e não há uma tendência de convergência desses investimentos, principalmente quando comparados aos esforços de países como Estados Unidos e Alemanha. O quadro brasileiro se reproduz, apesar de diferenças, em praticamente todos os países em desenvolvimento.

Os exemplos internacionais mostram que esse quadro pode ser alterado de forma significativa pela adoção de medidas de forte impacto pelo Estado e pelo setor privado. As experiências como as da Coreia do Sul e da China registram pontos de inflexão importantes no seu esforço de investimento em $\mathrm{P} \& \mathrm{D}$, desde os anos 2000, cujos resultados permitiram reverter, ainda que parcialmente, a tendência de seu histórico afastamento da fronteira mundial. 


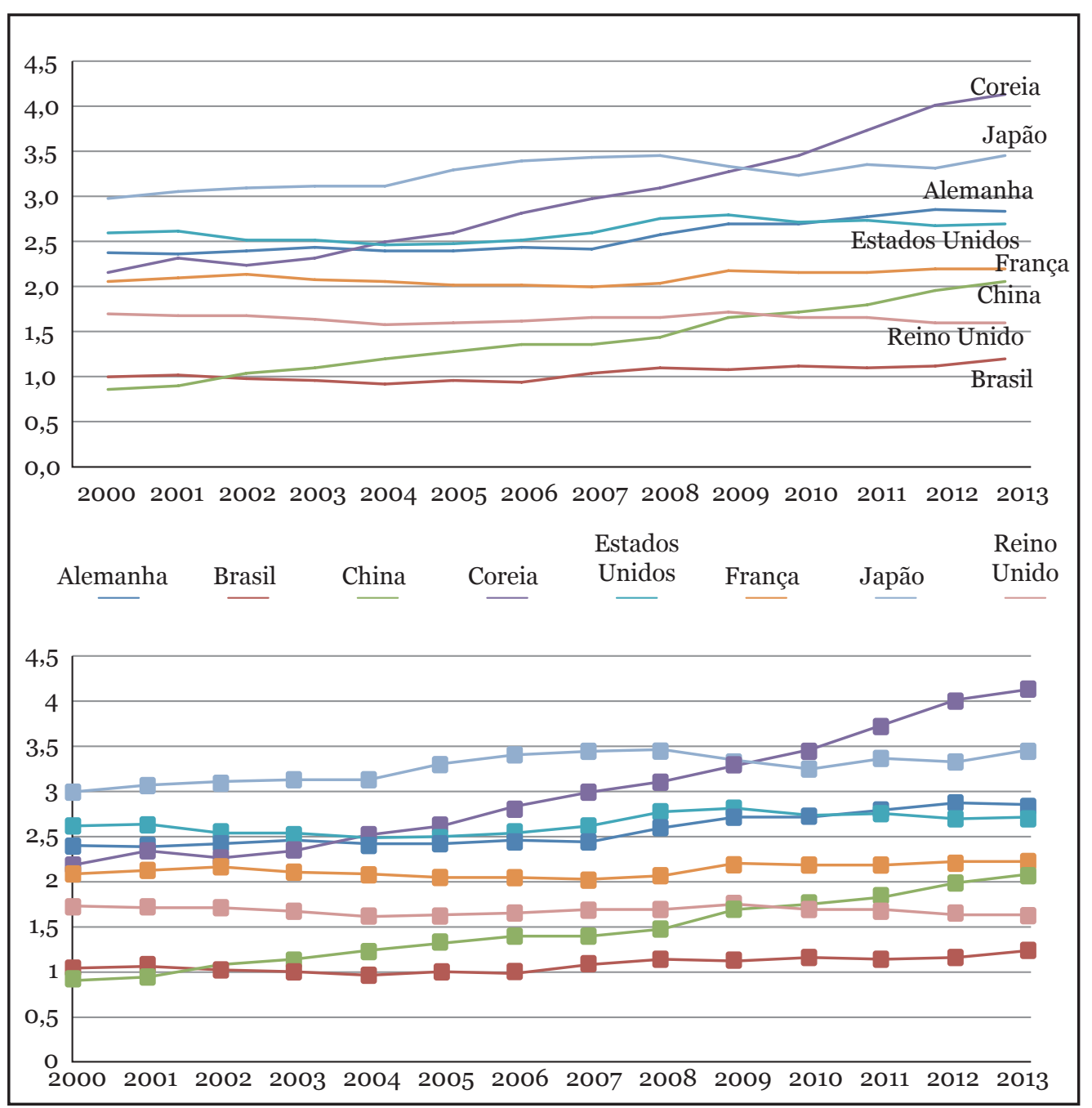

Gráfico 1. Dispêndios em P\&D em relação ao PIB (2000-2013, em\%). Fonte: MCTI. Elaboração própria.

No que tange à produção científica nacional, na última década o crescimento foi extremamente significativo. Em números absolutos, entre 2000 e 2014 o número de artigos de pesquisadores brasileiros publicados em periódicos indexados internacionalmente quadruplicou (passando de 13.943 para 59.736 artigos). Em 2000, o Brasil ocupava a $17^{\mathrm{a}}$ posição em relação à produção científica mundial e respondia por 0,76\% dos artigos publicados em periódicos internacionais. Em 2006, o país passa para a $15^{\mathrm{a}}$ posição (com $1,71 \%$ da produção mundial) e, em 2014, para a $13^{\mathrm{a}}$ posição (respondendo por 2,29\% da produção científica mundial). Em número de citações, porém, o país ainda precisa avançar, pois o impacto da produção tem evoluído de forma menos proeminente. 


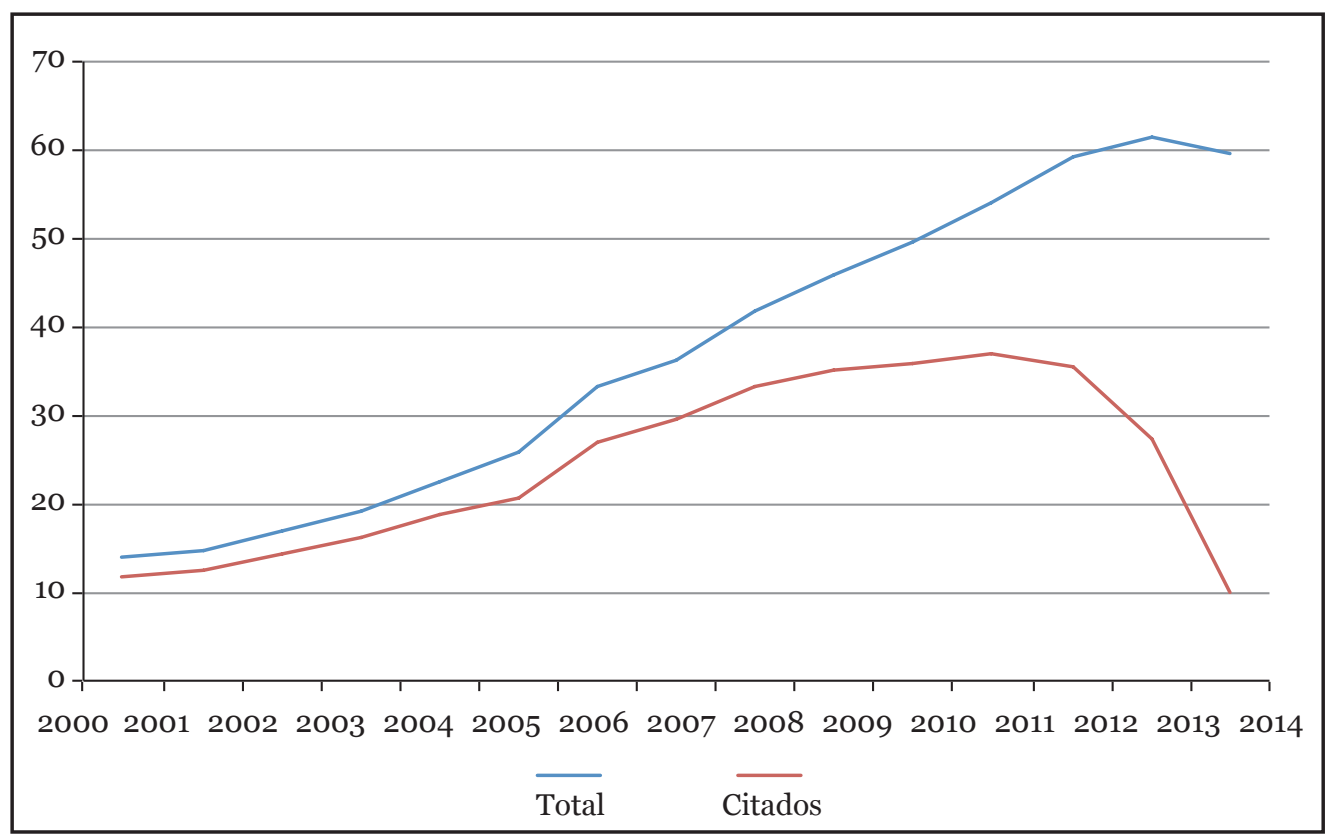

Gráfico 2. Número de Artigos e Citações (2000-2014). Fonte: Baseado no SCImago Journal \& Country Rank. Elaboração própria.

No período de 2000 a 2014, os pedidos de patente junto ao Instituto Nacional de Propriedade Intelectual (INPI) passaram de 20.854 em 2000, para $23.152 \mathrm{em}$ 2006 e $34.050^{1}$ em 2014. O crescimento é de 63\% no período de 2000 a 2014 e muito inferior ao registrado na produção científica. O depósito feito por residentes no país teve desempenho ainda pior, com crescimento de apenas 24\% (7.974/6.449), muito inferior ao crescimento da produção científica (328\%).

Deve ser ressaltado que em 2008 o Brasil ultrapassou 160 publicações por milhão de habitantes de acordo com a base Web Of Science. Este é um indicativo relevante da massa crítica necessária para o desenvolvimento científico e tecnológico. Este limiar é, entretanto, móvel e crescente no mundo. No caso do Brasil, ainda permanece forte desconexão entre a produção científica e a tecnológica. Na China, por exemplo, o número de pedidos de patentes tem crescimento percentual maior que a publicação de artigos, no período de 1996 a 2012.

1 Dados preliminares. 


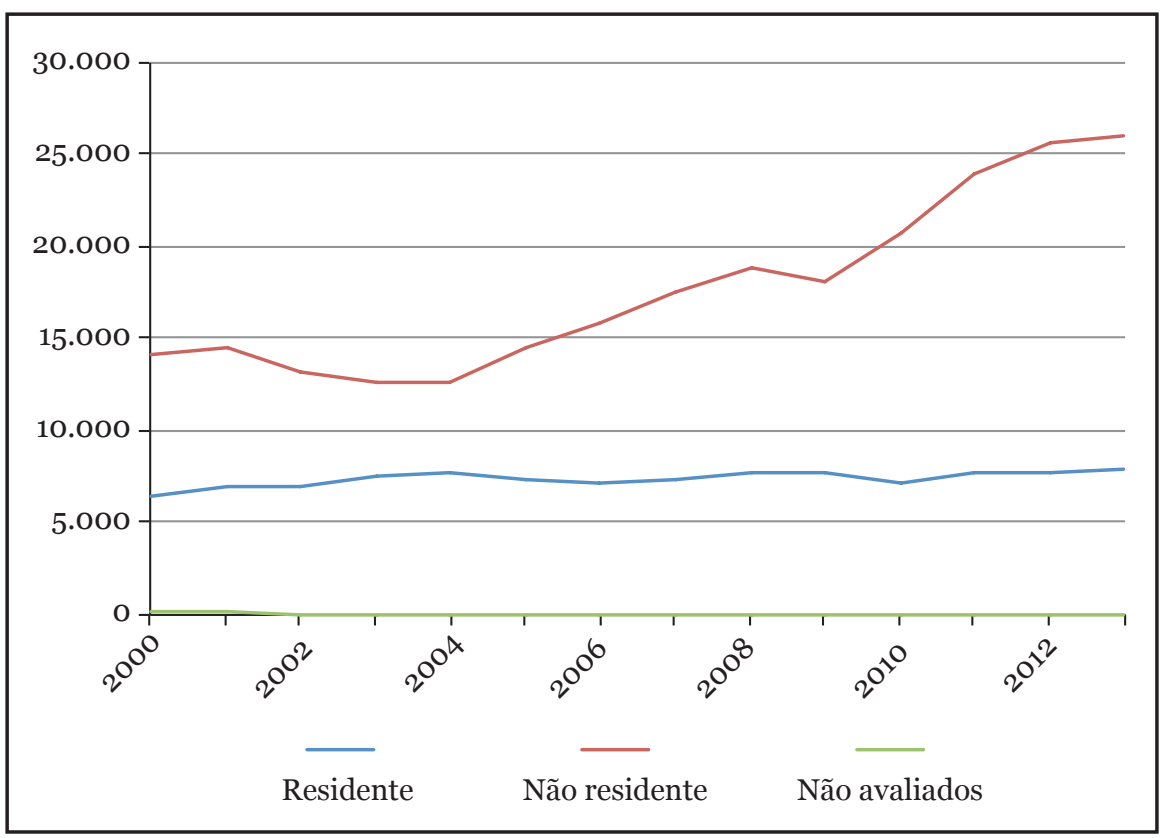

Gráfico 3. Pedidos de patentes depositados no INPI (por origem do depositante, 20002013). Fonte: MCTI. Elaboração própria².

O Brasil está em uma posição intermediária em relação ao mundo quando são olhados conjuntamente indicadores de pesquisadores/mil habitantes, gastos em P\&D como proporção do PIB e escala de P\&D (OECD, 2015). Isso significa que é possível incentivar a ambição da CT\&I no Brasil para impulsionar a produtividade e continuar o processo de distribuição de renda. Vale ressaltar que ainda é relativamente baixa a participação do setor empresarial nos esforços de P\&D no Brasil.

Mesmo com o crescimento acelerado do MCTI (que viu o Fundo Nacional de Desenvolvimento Cientifico e Tecnológico - FNDCT - multiplicar por 20 seus recursos nos últimos 10 anos) e a entrada de novos personagens com peso no mundo da pesquisa científica (como os Ministérios da Defesa, da Agricultura, da Educação e da Saúde, dentre outros), o conjunto do sistema ainda opera muito abaixo do necessário e sem estabilidade, ressentindo-se da falta de previsibilidade para o fluxo de recursos capazes de alimentar os equipamentos instalados, adquirir outros ou de formar e absorver os novos pesquisadores titulados anualmente. Algumas projeções indicam que se não elevarmos o padrão, alcançaremos a média atual dos países da Organização para Cooperação e Desenvolvimento Econômico (OCDE) em 2036.

2 Não avaliados por não identificação do $1^{\mathrm{o}}$ depositante ou da origem do $1^{\mathrm{O}}$ depositante. 


\section{POR INCIATIVAS MAIS ROBUSTAS E TRANSFORMADORAS}

É reconhecida a relação íntima que existe entre as dimensões e desempenho da comunidade acadêmica e os indicadores de desenvolvimento econômico e social dos países. Como mostrado anteriormente, no Brasil, apesar dos avanços significativos, é urgente a elevação do número de pesquisadores, da qualidade da pesquisa científica, dos instrumentos voltados para o apoio da Ciência e dos recursos envolvidos.

A Ciência brasileira precisa crescer rapidamente, em estreita relação com as redes globais de produção de conhecimento novo, e em sintonia ampla com o esforço que faz o Brasil para melhorar a qualidade de vida de sua população e o grau de civilização de sua sociedade. Dentre as inúmeras propostas registradas pela IV Conferência - e referendadas pela Estratégia Nacional de CT\&I (MстI, 2010) - ganham destaque:

- Aumento dos investimentos em cooperação internacional;

- Programa especial, em bases competitivas, para apoiar planos de excelência das instituições de pesquisa e universidades, com o objetivo de situá-las entre as melhores do mundo;

- Criação de centros de pesquisa ambiciosos, coordenados com universidades e redes de pesquisa - Institutos Nacionais de Ciência e Tecnologia (INCT's);

- Amplo programa de brain gain, de modo a promover mecanismos de absorção de pesquisadores estrangeiros.

Com seu amadurecimento, o sistema nacional de pesquisa passou a sofrer, a um só tempo, intensa pressão por talentos, projetos e estratégias de longo alcance, assim como por recursos estáveis. Nesse sentido, as propostas que visam potencializar o atual modo de produção nacional de C\&TI devem ser capazes de atuar, simultaneamente, em quatro aspectos críticos que constituem a base de um sistema de produção de conhecimento e inovação:

- Infraestrutura

- Fomento

- Recursos humanos qualificados

- Inovação 
Sem a extensão e consolidação permanente dessas múltiplas dimensões, que são essenciais para a produção científica e tecnológica de qualidade, fortes desequilíbrios irão comprometer todo o sistema. É a articulação dessas dimensões que permite maximizar os investimentos feitos em laboratórios e equipamentos, desenhar e implementar novas modalidades de apoio, executar programas para fortalecer elos mais frágeis, incorporar novas gerações de pesquisadores e incentivar a busca de patentes, de licenciamentos e de resultados claros para a economia e a sociedade.

Nessa direção, como anunciado pela IV Conferência Nacional de C\&T, é essencial para o país a ênfase:

i) na extensão e aprofundamento da qualificação de pesquisadores, em seus múltiplos níveis e modalidades, e na sua absorção pelas instituições científicas, pela sociedade e pelo setor econômico;

ii) na superação da instabilidade de recursos para viabilizar programas de formação sistêmica de pesquisadores e a ampliação do parque de equipamentos instalado;

iii) no estímulo à formação de redes e à cooperação com base em laboratórios multiusuários e transdisciplinares, articulados por núcleos de competências sólidos e de classe mundial;

iv) no aprofundamento da internacionalização da nossa produção científica e tecnológica;

v) na execução de programas voltados para intensificar a articulação com empresas, de modo a gerar tecnologia e inovação;

vi) na busca por maior impacto da produção científica e tecnológica nacional, quer em termos de uma ciência de classe mundial, capaz de contribuir significativamente para o avanço do conhecimento, quer em termos de melhoria da qualidade de vida de nossa população, quer em termos de maior competitividade e melhor inserção internacional de nosso sistema produtivo; e, como resultado do esforço de anos;

vii) na concentração de esforços materiais e humanos em áreas-chave para diminuir a distância que nos separa da geração de conhecimento na fronteira da Ciência e da Tecnologia mundial.

O Brasil necessita dar um novo e ousado passo, que ganhará maior relevância e significado quanto mais for marcado pela preocupação básica de manter ativo e saudável todo um sistema capaz de atrair e manter seus talentos, com o objetivo 
permanente de gerar impactos relevantes para toda a sociedade. Sabemos que a C\&T brasileiras sofrem pressões tanto da produção estruturada dos países desenvolvidos, quanto do rápido avanço de muitos países emergentes que, em vários domínios, já conseguem atuar nas fronteiras do conhecimento. Por isso, precisamos urgentemente avançar.

É preciso implementar programas capazes de atrair cérebros do exterior, completar a infraestrutura científica nacional, dotar o país de grandes e novos centros de pesquisa e dar oportunidade a milhões de estudantes e pesquisadores para gerar a Ciência e a Tecnologia de que tanto precisamos.

Somente um plano com prioridades claras será capaz de superar a pulverização atual do investimento e estimular toda uma nova geração de pesquisadores e cientistas. A experiência internacional e os avanços no Brasil permitem-nos afirmar que é possível, em uma geração, colocar o Brasil na fronteira do conhecimento em áreas críticas como Energia e Sistemas Ambientais, Biotecnologia, Inteligência Artificial e Robótica, Nanotecnologia e Manufatura Digital, Redes e Sistemas de Computação, Medicina e Neurociências, e Aeroespacial. Em torno desses campos de pesquisa é possível mudar estruturalmente nossa CT\&I, de modo a alimentar (e ser alimentada) por uma economia e um ambiente inovador de que tanto necessitamos.

\section{OS CAMINHOS DA INOVAÇÃO}

Tornou-se quase um mantra no Brasil dos últimos anos afirmar que não há nem haverá país forte sem uma indústria forte. Uma indústria capaz de competir no cenário internacional e de oferecer bens e empregos de qualidade, que ajude a elevar a produtividade e a sustentar o crescimento da nossa economia. As chamadas políticas industriais buscaram exatamente esse fortalecimento. Com foco na inovação e na tecnologia, se dispuseram a elevar o patamar da nossa indústria, diversificar, modernizar e globalizar o sistema produtivo de modo a aumentar de forma consistente a produtividade da economia.

A retomada das políticas de inovação em 2004, após um quase exílio de mais de 25 anos, esteve longe de ser tranquila. Não somente pela controvérsia que suscitaram, mas também pelas resistências no meio empresarial, acadêmico e mesmo no interior das instituições públicas e órgãos de governo.

O lançamento da Política Industrial, Tecnológica e de Comércio Exterior (PITCE) estimulou um vivo debate dentro e fora do ambiente público naquele começo de século. E permitiu que a debilidade e mesmo o despreparo da máquina 
estatal brasileira e de grande parte dos agentes econômicos privados se tornasse flagrante desde os primeiros passos na direção de políticas que ajudassem na superação de deformações estruturais profundas.

Não se tratava apenas de recuperar ou retomar o fio de continuidade de uma linhagem de políticas industriais que haviam florescido no período do nacional desenvolvimentismo. As políticas industriais contemporâneas, se quiserem ser efetivas, precisam apresentar-se claramente como distintas das anteriores. Não somente porque o funcionamento da economia mostra-se muito diferente dos anos 1950, 1960 e 1970. Mas, fundamentalmente, porque o Brasil é outro. É um país democrático e muito mais poroso às novas tendências internacionais, em que os fluxos de conhecimento passaram a fazer parte de sistemas produtivos em constante mudança.

No início dos anos 2000, tratava-se, como hoje, do desafio de elaborar políticas para um ambiente mais complexo, com atores novos, condicionantes inéditos e nem sempre bem conhecidos, em meio a cadeias de valor globais que inexistiam no período anterior, em que o rápido crescimento da nossa economia era fruto do esforço da industrialização. O Brasil conseguiu criar um parque industrial heterogêneo, diversificado e articulado. O passo seguinte, o da sofisticação, da qualidade, da tecnologia, inovação e alta produtividade, configurou-se como um alvo ainda distante, que permanece ainda sem desenlace positivo desde o esgotamento do desenvolvimentismo.

Em 2004, o mundo industrial precisava de um choque de inovação. Hoje, mais de dez anos depois, esse desafio continua presente. Novas instituições surgiram. Leis de impacto, que viabilizaram novas iniciativas para transformar nossa indústria. E também muitas mentes, impregnadas por uma cultura mais aberta à inovação e ao desenvolvimento tecnológico. E isso apesar da insegurança e instabilidade de muitas políticas governamentais que, muitas vezes, tendem a retomar componentes do velho protecionismo e secundarizar os programas de inovação.

Essa foi a marca da Brasil Maior, em que políticas horizontais se sobrepuseram às de inovação, e desoneraram setores industriais inteiros, de forma regressiva, uma vez que os incentivos subsidiaram mais as empresas menos inovadoras.

A indústria não pode mais se contentar com mudanças cosméticas. A obrigatória disputa pelo mercado internacional exigirá que as empresas reorientem suas estratégias de modo a acompanhar a revolução da manufatura que avança pelo mundo. Para isso, mais do que nunca, o Brasil precisa avançar rumo a uma economia amigável à inovação. 
A redução da atividade econômica desde 2010 dificultou a ampliação das políticas de inovação e ameaça concretamente sua continuidade nos dias de hoje. $\mathrm{O}$ resultado é que a distância em relação aos países mais avançados voltou a aumentar. Se não corrigir a rota, de modo a ajudar a indústria a se reinventar, a ciência e a tecnologia a desabrocharem e a inovação a se enraizar no coração das empresas, o Brasil corre o risco de estagnar nas margens do século XXI.

\section{REFERÊNCIAS BIBLIOGRÁFICAS}

ACADEMIA BRASILEIRA DE CIÊNCIAS. POR UMA POLÍTICA DE ESTADO PARA CIÊNCIA, Tecnologia e Inovação: contribuições da $\mathrm{ABC}$ para os candidatos à Presidência do Brasil. Rio de Janeiro, 2014. Disponível em: < http://www.abc.org. br/IMG/pdf/doc-5793.pdf $>$.

ARBIX, Glauco; VARON, Joana. "Finlândia: o salto para uma economia baseada no conhecimento". In: ARBIX et al. (Org.). Estratégias de Inovação em sete países: EUA, Canadá, Irlanda, França, Reino Unido, Finlândia e Japão. Brasília: ABDI, 2009. p. 156-185. Disponível em: <http://www.abdi.com.br/Estudo/MOBITnovofinal.pdf>. DE NEGRI, Fernanda; CAVALCANTE, Luiz Ricardo (Org.). Produtividade no Brasil: desempenho e determinantes. Brasília: Ipea, 2014, v. 1.

DE NEGRI, João. “Avançar ou avançar na política de inovação”. In: BARBOSA et al. (Org.). Indústria e Desenvolvimento Produtivo no Brasil. Rio de Janeiro: Elsevier: FGV, 2015. MCTI. Nota Informativa sobre Evolução dos dispêndios nacionais em C\&T e P\&D no período 2000 A 2013. Brasília, 2015. Disponível em: <http://www.mct.gov.br/upd_ blob/o237/237332.pdf>.

Consolidação das recomendações da $4^{a}$ Conferência Nacional de Ciência e Tecnologia e Inovação para o Desenvolvimento Sustentável; Conferências nacional, regionais e estaduais e Fórum Municipal de C,T\&I. Brasília: Ministério da Ciência e Tecnologia / Centro de Gestão e Estudos Estratégicos, 2010.

NATIONAL ECONOMIC COUNCIL. A Strategy for American Innovation: Driving Towards Sustainable Growth and Quality Jobs. Executive Summary. 2009. Disponível em: <https://www.whitehouse.gov/administration/eop/nec/ StrategyforAmericanInnovation>.

OECD. OECD SCIENCE, Technology and Industry Scoreboard 2015. Paris: OECD Publishing, 2015. Disponível em: www.keepeek.com/Digital-Asset-Management/oecd/ science-and-technolo gy/oecd-science-technology-and-industry-scoreboard-2015_ sti_scoreboard-2015-en\#page1. 
United States. OECD Science, Technology and Industry Outlook 2014. Paris: OECD Publishing, 2014. Disponível em: <http://www.keepeek.com/ Digital-Asset-Management/ oecd/science-and-technology/oecd-science-technologyand-industry-outlook-2014_sti_outlook-2014-en\#page1>.

Policy Responses to the Economic Crisis: Investing in Innovation for LongTerm Growth. Paris, 2009. Disponível em: <http://www.oecd.org/sti/42983414.pdf>. PAES DE BARROS, Ricardo. Sobre o processo de desenvolvimento inclusivo no Brasil na última década. Notas Estratégicas no. 3. Brasília: SAE, 2014. Disponível em: <http:// www.sae. gov.br/imprensa/noticia/destaque/sobre-o-processo-de-desenvolvimentoinclusivo-no-brasil-da-ultima-decada/>.

PNUD. Índice de Desenvolvimento Humano Municipal Brasileiro. Brasília: PNUD, Ipea, FJP, 2013.

SCIMAGO JOURNAL \& COUNTRY RANK. Disponível em: <http://www.scimagojr.com/>. WHITE HOUSE. The Recovery Act: Transforming the American Economy Through Innovation. 2010. Disponível em: <https:/www.whitehouse.gov/sites/default/files/ uploads/Recovery_Act_Innovation.pdf $>$.

Recebido para publicação em: 09/10/2015. Aceito para publicação em: 16/11/2015. 